\title{
Training Online Physical Educators: A Phenomenological Case Study
}

\author{
Tyler Goad and Emily Jones \\ College of Physical Activity and Sport Sciences, West Virginia University, Morgantown, WV, USA \\ Correspondence should be addressed to Emily Jones; emily.jones@mail.wvu.edu
}

Received 10 March 2017; Revised 31 May 2017; Accepted 12 June 2017; Published 16 July 2017

Academic Editor: Auli Toom

Copyright (C) 2017 Tyler Goad and Emily Jones. This is an open access article distributed under the Creative Commons Attribution License, which permits unrestricted use, distribution, and reproduction in any medium, provided the original work is properly cited.

Online physical education (OLPE) presents a unique set of challenges in translating traditional physical education to a digital space, all while meeting the same benchmarks, curriculum, and assessment standards of traditional courses. Currently, limited research exists investigating how physical educators are formally trained to deliver content online. Therefore, the purpose of this study was to describe the experiences and perceptions of students and instructor of a graduate-level OLPE teacher education (OLPETE) methods course. A phenomenographic research design was employed to examine the social phenomenon of one OLPETE methods course at a midwest midmajor college. Participants in this study were an instructor of OLPETE methods course and former students who had completed the course. Data for the case study were collected through semistructured interviews and inductive content analysis was employed to analyze the qualitative data. Results revealed four categories describing the lived experiences of those involved: (1) Modeling Online Instructional Practices, (2) Instructor and Student Interactions, (3) Transitioning Pedagogical and Content Knowledge Online, and (4) Navigating Instructional Tools and Technology.

\section{Introduction}

Teachers across the country are encountering a new generation of learners who have never known life without modern conveniences and technologies such as personal computers, mobile devices, streaming media, and the World Wide Web. Learners born into this generation have been termed "digital natives" and are said to have been "immersed in technology all their lives, imbuing them with sophisticated technical skills and learning preferences" [1, p. 775]. They are considered to be proficient multitaskers and active learners and to be dependent on technologies for information access and communication [2]. Considering this, some have raised questions about whether current educational approaches and traditionally trained educators are equipped to meet the needs of these learners. While instructional methods and effective pedagogical strategies have remained largely unchanged, modern technologies have influenced the modes in which educators can connect, interact, and communicate with learners.
Web-based learning management systems (LMS) have transformed the potential for teachers to present subjectspecific content to learners in synchronous and asynchronous formats. Reaching the new generation of learners in online and distance formats, educators have greater access to tools and technologies that facilitate content organization, delivery, and interactive modalities. Considering this platform, educators are also confronted with the new and dynamic nature of establishing not only meaning interactions between student and content, but also student-to-student and student-toinstructor interactions [3]. Within online learning, programs are defined by the proportion of course time delivered faceto-face versus online. As a result, Allen and Seaman [4] have defined four types of courses: traditional ( $0 \%$ online), webfacilitated (1-29\% online), blended/hybrid (30-79\% online), and online ( $>80 \%$ online). Research in the area of online and distance education has provided insights into the dynamic qualities of teaching and learning in the online environment [5]. Specifically, scholars have advocated for pedagogical practices in online settings that focus on student-centered 
constructivist approaches [3] that promote interactive environments and relevant/authentic learning experiences [6].

During the 2009-2010 school year, 1.5 million K-12 students were enrolled in online or hybrid programs [7]. This number includes core curriculum courses as well as specialized content areas such as music, art, and physical education [7]. Not all disciplines, however, have fully embraced the potential of online education. Physical education, for example, a discipline largely known for the development of motor skills and movement competencies and fostering physical activity and physical fitness, has been slow to adopt online education. Albeit slow, there is a growing trend of physical education programs using online platforms. This trend has been observed in practice as well as in the literature since 2010 and has come to be known as online physical education, or OLPE.

Some physical education pedagogists and researchers view OLPE with a healthy degree of apprehension and skepticism, even referring to OLPE as a bit of an oxymoron [7]. Yet, OLPE has become increasingly prevalent. As of 2016, 31 states allow physical education credits to be taken online, a ninestate increase from 2010 [8]. Seventeen of the states that allow online physical education require OLPE to be delivered by a certified physical educator and six are reportedly aligned with national standards [9]. The most prevalent model of OLPE instruction is the hybrid method, also referred to as blended learning [7, 10-12]. The hybrid method is student-centered with majority of course work occurring outside of class and periodic in-person meetings for assessment, instruction, and safety guidelines $[7,12,13]$. The most common form of OLPE is a fitness elective, generally known as wellness for life [12, 14 ], and has a primary objective of improved health behaviors and fitness levels.

Documented apprehensions surrounding OLPE range from student accountability, course rigor, safety and liability issues, retention rates, and, most commonly noted, the concern about how students would achieve national and state-level content standards and outcomes [7, 12, 15-17]. Just as the landscape of education has evolved for classroom and face-to-face teachers, individuals developing, delivering, and evaluating OLPE courses will need to identify and implement innovative teaching strategies aimed at addressing and eradicating these concerns $[7,12,15,18]$.

The scope of research in the area of OLPE is somewhat limited, but as more dimensions of OLPE are explored, the body of research gains momentum. Current research in OLPE has provided insights into factors such as student and teacher perceptions, cognitive and fitness gains of enrolled students, and instructional strategies and delivery methods [9]. Recent descriptive studies in OLPE have examined student and teacher perceptions of how to provide online physical education. A case study by Williams in 2014 followed up four K12 OLPE instructors and examined their day-to-day practices and "real-world" experiences. Four categories emerged from the data: (1) similar professional/career pathways to OLPE teaching, (2) individualized instruction provided to students, (3) teacher-guided student choice, and (4) teacher-facilitated student success [19]. Williams suggested that the OLPE instructor "should have a strong ability to type, enjoy sitting in front of a PC, and interested in grading written work, and communicating in different formats" [19, p. 203]. Some researchers suggest that these identified skillsets and teacher functions may conflict with preservice teachers' perceptions of what is essential for a career within physical education [20].

Daum and Buschner [15] conducted a study of 9-12thgrade OLPE instructors $(N=32)$ to investigate high school OPLE course content, instructional design, and teaching methods. Key findings revealed a lack of motor skill development and limited student participation, and less than $30 \%$ of the instructors indicated meeting the recommended $225 \mathrm{~min}$ utes of weekly physical education. Participants expressed concerns about OLPE's ability to achieve the national standard that focuses on the psychomotor domain (SHAPE America Standard 1). Furthermore, participants described that limited technology skills prevented students from completing the course and/or contributed to frustrations related to course technology. The OLPE instructors perceived online education as valuable but had limited experience prior to accepting their positions. Sixty-three percent of the participants indicated that they had only been teaching OLPE for up to two years. The authors suggested a need for training and professional development for physical educators, particularly for those new to online education [15].

The delivery of physical education online presents a challenge for teachers to transition traditional movementoriented content [21] and student experiences to a virtual environment. This task seems quite monumental as teachers would need to design learning experiences that facilitate student achievement of standards and grade level outcomes identical to those within traditional/face-to-face physical education environments [7, 12]. Considering the unique instructional and contextual variables of physical education, teachers of OLPE must have an understanding of the potential barriers, benefits, and realistic student outcomes online. In 2007, the National Association for Sport and Physical Education (NASPE) developed the Initial Guidelines for Online $\mathrm{PE}$, which provide recommendations for content, assessment, technology, instructional design, and necessary support and infrastructure. These guidelines have been used to inform the development of OLPE courses and provide a framework for evaluating courses currently being delivered. Considering that 1.5 million K-12 students in the US enrolled in online or hybrid programs and the growing trend of schools offering OLPE [7], there remain few empirical studies examining the efficacy and effectiveness of OLPE-focused teacher training initiatives.

Within formal teacher training programs, negotiations are ongoing regarding the limited resources, capacity, and curricular space. Recent studies have shown that physical education training programs are struggling to effectively introduce and model the best practices of technology integration $[22,23]$. While teacher training may address technology in physical education, Williams [19] suggested that preservice teachers remain inadequately prepared to translate content to an online environment and thus future training related to OLPE is needed. Results from a national survey targeting teacher education programs efforts preparing preservice teachers for online education suggest that $1.3 \%(N=522)$ 
have field experiences for preservice teachers in online education, while an additional $13 \%$ indicated current plans to integrate virtual field experiences [24].

To date, no research exists on how physical educators are formally trained to deliver content online. This gap in the literature suggests a need for increased exposure and training in the design and delivery of OLPE. Therefore, the purpose of this study was to describe the experiences and perceptions of students and instructor of a graduate-level OLPE methods course.

\section{Methods}

Qualitative research methods were used to examine the experiences and perceptions of students and an instructor of a graduate-level OLPETE methods course $[25,26]$. Phenomenology is described by Patton [27] as a qualitative research method that focuses on individuals' meaning making within their lived human experience. Scholars who conduct phenomenological research explore, uncover, and interpret the individuals' cognitive processing regarding a common experience to reveal the essence of the phenomenon. This study used a variation of phenomenological research called phenomenography which was originally conceived by Marton as a method to "investigate the qualitatively different way in which people experience or think about various phenomena" [25, p. 31]. A phenomenographic study serves to describe the conceptions of those experiencing the phenomenon [25]. Phenomenography was developed in response to educational questions and is best known for investigating students and instructors' conception of experiencing a phenomenon $[25,28]$ rather than understanding the essence of the phenomena. Further, phenomenography argues that every person experiences phenomena differently and discerns that experience in their own way [28]. Therefore, investigating the perspectives of both the OLPETE instructor and the students collectively may facilitate a greater understanding of "the collective sum of ways of experiencing" [28, p. 635] that in turn will allow for exploration of participant experiences in relation to one another, not independent of each other. Application of a phenomenographic approach to the current study will assist in identifying instructor and student conceptions of the OLPETE methods course and may reveal aspects of the experience that are critical to the training and development of OLPE instructors and OLPETE methods courses.

2.1. Participants. Operational construct sampling was used in this study to identify and select a case that represented an example of "real-world examples of the constructs of interest" [27, p. 238]. In this case, the phenomenon was an online physical education teacher education (OLPETE) methods course. For a course to be considered an OLPETE methods class, there were four criteria that had to be met: (1) course is offered within the university/college physical education teacher education program; (2) instructor had a background/degree in physical education or a related field (e.g., health education, kinesiology, and recreation);
(3) course had been taught for at least two semesters; (4) course focuses on teaching methods and physical education subject matter. One midwest midmajor college was identified as meeting these criteria and had a required graduatelevel course titled Teaching Online Health and PE delivered by a physical education teacher/education faculty member. Participants in this study were an instructor of OLPETE methods course and former students who had completed the course. The instructor of record was contacted via email and agreed to participate in the study. Consent forms were signed by the participant and an interview time was scheduled at their convenience. Snowball sampling was used to recruit student participants as key informants [27].

OLPETE Instructor. "Professor M" began teaching online courses at a midlevel midwestern university in 1996 within a department that encompassed health, physical education, and recreation disciplines. During this time, this department was the only one offering online courses at the university, resulting in limited IT support and training. As online offerings became more prevalent at the institution, Professor M described professional development workshops offered through the IT department that focused on instructional strategies and online delivery. In the early 2000s, Professor M recognized a trend of online education and virtual learning within the high school setting, which prompted the development of online content courses as well as the online teaching methods course. Professor M delivered the graduate-level OLPETE methods course for the first time in 2012 and has enrolled approximately 25 students per semester.

Former OLPETE Students. Former students enrolled in the OLPETE course were identified as key informants of the lived experiences and perceptions of the OLPETE methods course. To recruit participants, Professor $\mathrm{M}$ sent an email to the students from her class roster across the past 2 semesters $(n=18)$. Of those invited to participate, five completed the electronic demographic survey and three agreed to participate in follow-up interviews with the lead investigator.

\subsection{Instrumentation}

Semistructured Interviews. The phenomenographic study was designed to focus on both instructor and student experiences within an OLPETE methods course; to do so, two semistructured interview guides were developed (instructor and students). Questions were intentionally formed to be general and broad to avoid researcher's bias and increase the authenticity of participant responses [29]. Both interview guides were informed initially by the components within the 2007 NASPE Initial Guidelines for Online Physical Education. The interview guide for the OLPETE instructor included questions related to faculty background, perceptions of required credentials of OLPE instructors, and student readiness for an OLPETE course. Questions pertained to the instructors' experiences delivering the OLPETE course from the perspective of curriculum and instruction, assessment, and equipment/technology. The interview guide for student 
TABLE 1: Student participant demographics, survey respondents.

\begin{tabular}{lcccc}
\hline Sex & Age range & Began using computers regularly & OLPE teaching experience prior to enrollment & Currently teaching OLPE \\
\hline Female $^{*}$ & $42+$ years & College & No & Yes \\
Female & $24-29$ years & High school & No & No \\
Male* $^{*}$ & $36-41$ years & College & No & No \\
Male & $30-35$ years & Middle school & No & No \\
Male & $30-35$ years & Elementary school & No & No \\
\hline
\end{tabular}

${ }^{*}$ Interviewee.

participants focused on students' backgrounds, their perceptions of learning to teach OLPE, and their experiences within the OLPETE course. Interview guides were pilot-tested with a physical education teacher education faculty and graduate students prior to data collection and modified for item clarity as appropriate.

Student Demographic Survey. A 10-item electronic survey was developed to capture student participant background and demographic information. The survey included closeended demographic items such as age, gender, computer use, and information on teaching/employment status. Background information items on the survey included openended questions related to participant concerns of teaching OLPE and technologies perceived to be critical to teaching OLPE. For the purposes of this study, only the close-ended demographic items were analyzed and reported.

2.3. Data Collection Procedures. Following approval from the West Virginia University's Institution Review Board, data collection procedures commenced. Initial contact with the potential instructor of an OLPETE course was an email invitation that included a description of the study and a consent form. Upon response, the instructor interview guide was sent along with a request to schedule a phone interview. A 90-minute semistructured interview was conducted between the lead investigator and the instructor of the OLPETE course. The interview was audio-recorded and transcribed verbatim (Professor M's transcript: 21 pages, 9,488 words); pseudonyms were given to the participant and identifiable information was removed.

Following the OLPETE instructor interview, data collection with former OLPETE students began. To recruit student participants, initial contact was made by the OLPETE instructor via email that was sent to formerly enrolled OLPETE methods students $(n=18)$. The email was sent on behalf of the lead investigator and explained the purpose of the study and included a link to a brief electronic demographic survey and an invitation to participate in a 60-minute follow-up telephone interview. A reminder email was sent two weeks later to potential participants. Five participants completed the survey (27\% response rate; see Table 1 ), and of them three agreed to participate in a follow-up phone interview with the lead researcher. Due to the unavailability and lack of participant responsiveness, only two student interviews were conducted. Sixty-minute telephone interviews were conducted by the lead researcher with each student participant. Interviews were audio-recorded and transcribed verbatim (Ellen's transcript: 12 pages, 5,917 words; Connor: 12 pages, 5845 words); pseudonyms were given to participants and all identifiable information was removed. Following transcription, a summary of the individual interviews was sent to all participants to verify the transcribed interview content [29].

2.4. Data Analysis. After all interviews had been completed and transcribed verbatim, investigators began analysis by reading and rereading the entire set of interviews. Analysis of the phenomenographic data is done at the level of the transcript, considering the context of the transcript as a whole. Independent members of the research utilized inductive content analysis and constant comparison [30] to begin analysis of the transcripts [27, 31] and to identify initial categories and emergent themes from the data [30, 32]. Methods were employed during this first cycle of coding to bracket the researcher's biases, examine the most distinctive characteristics of the data, and reflect the participant's conceptions of the OLPETE methods course. Initial categories were discussed among researchers to explore the similarities and differences among the groups until an agreement about the coding protocol was established and verified. The second cycle coding employed a thematic analysis. Quotes from the data were extracted that reflect the most essential and distinctive aspects of the structural relationship between instructor and students experiences and the OLPETE methods course. Marton described the process as having "quotes sorted into piles, borderline cases are examined, and eventually the criterion attributes for each group are made explicit" [25, p. 43]. The codes were sorted and resorted so that categories were defined in terms of core meanings (see Table 2) and until the following criteria were found: (1) each category represented a distinct way of understanding the experiences within the phenomenon, (2) the categories were logically related, and (3) the outcomes were parsimonious $[33,34]$. Trustworthiness of interview data was ensured through member checking [29] and peer debriefing of codes and initial category development throughout data analysis, towards the important end of enhancing the quality of the methodological decisions, research design, and implementation [27, 35].

\section{Results and Discussion}

As a result of the qualitative analysis of the instructor and student interviews, four categories regarding participant experiences within the OLPETE methods course emerged 
TABLE 2: Total interview recording selections.

\begin{tabular}{lcc}
\hline Category & Instructor $(n=1)$ & Students $(n=2)$ \\
\hline Modeling of Online Instructional Practices & 24 & $18($ Conner $)$ \\
& 15 (Ellen) & $11($ Conner $)$ \\
Instructor and Student Interactions & 6 (Ellen) \\
Transitioning Pedagogical and Content Knowledge Online & 10 & $12($ Conner $)$ \\
Navigating Instructional Tools and Technology & 26 & 22 (Ellen) \\
& & 13 (Conner) \\
\end{tabular}

from the data. The categories were (1) Modeling of Online Instructional Practices, (2) Instructor and Student Interactions, (3) Transitioning Pedagogical and Content Knowledge Online, and (4) Navigating Instructional Tools and Technology.

3.1. Modeling of Online Instructional Practices. Although online course delivery is common in higher education, there is great variability in the quality of course design and instructional and pedagogical approaches. Further, research provides that, within teacher training programs, specifically PETE, there is a lack of awareness and there are generally negative perceptions of OLPE's effect on the field [36]. Reflections from the course instructor reflected great intentionality in planning and delivering content and learning activities that represent online teaching practices. This became particularly important for enrolled students who have minimal online education experience and limited expectations of OLPE. Interviewed students reported no previous training or experience with online education. Connor reflected that he "stumbled upon online PE" while reviewing the course offerings and questioned its usefulness and feasibility. Specifically, he recalled thinking, "What the heck is that?" and questioned the viability of OLPE by asking himself, "Is that good for physical education that schools are going to offer where [students] don't have to come to class?" A different type of uncertainty was described by Ellen, who described the notion of OLPE as "overwhelming" and generated "a lot of anxiety at what I was about to get myself into." This finding echoes work by Kooiman et al. that buy-in from practitioners may be low due to concerns about OLPE "displacing PE teachers with web proctors" [37, p. 3].

In response to the student apprehensions, the instructor prioritized modeling online teaching practices and established instructor and student expectations throughout the semester. An example of this was the signature course project that required students to develop a six-unit OLPE course including student-designed course syllabus, instructional materials, assignments, and assessments. To facilitate student success, progressive weekly learning modules were embedded in the OLPETE course and allowed students to "learn and build" their online course throughout the term. Professor $M$ structured earning activities and assignments that walked students through constructing course introductions, syllabi, and welcome videos for the culminating assignment. These activities mirrored the course design and instructor practices that students experienced at the start of the OLPETE course.

To promote student learning, Professor M described, "I have to tell them and show them; I even give them a roadmap, video roadmap" to help students know exactly what to do and what it should look like. This approach allowed students to examine existing course materials and determine which aspects they would use to present and communicate their content online. Connor reflected on how Professor M modeled the process of course development and necessary technology use to him and his classmates:

[She] would give us examples of what ... she did in her video and where she was finding stuff. And she gave us a plethora of areas to find things... to add to our course. Basically she would give us the little feeder [starting point] and then we'd go search for it. And, then when we'd go search for it on our own. You'd find out that she only gave us one, but there are hundreds of ways you can do something. Then we would bring it to the table and create our own as our final project. Basically...watch what she does, take her lead, and then go from there.

Based on findings from Wicks [38], online instructors reported tasks to include a wide range of instructional functions, including guiding and personalizing learning, developing group projects, making constant adjustments to course resources, and creating and facilitating group discussions [38]. Throughout the course, Professor M designed independent and authentic assessments. Professor M reflected, "One of the challenges in any online course, is getting the student to be interactive with the material." To accomplish this, she created learning activities and assessments that forced students to engage with the content. One example was a virtual field trip that required students to research and create online resources that would connect the content and learners with family, friends, or others they would interact with outside of class. Conner described how he completed the virtual field trip assignment:

I did a field trip going to the grocery store versus going to Whole Foods, One of the other grocery stores that sells all natural foods. I snapped pictures and I interviewed some people at the different stores and then I tied that information 
to grocery stores [in my area] and embedded it into my field trip.

From the start of the OLPETE course onward, Professor $M$ created learning experiences for students that modeled instructional practices that promote active learning, which could be applied in the future. According to Hart [39], support from coworkers, family, and friends in online courses can help students manage academic workload and contribute to persistence. Support within the virtual community via course instructors and online classmates can also provide encouragement, assist with troubleshooting technical problems, and facilitate constructive feedback that provides a sense of camaraderie within the course.

3.2. Instructor and Student Interactions. Kennedy and Archambault [24] describe the mentor-teacher role in preservice teacher's online field experiences as a cognitive apprenticeship. Through this apprenticeship, preservice teachers observe online teaching practices, have opportunities to model their mentor teacher, and identify and reflect upon concepts presented. The mentor-teacher role in the development of preservice teachers is to make instructional method knowledge explicit, model effective strategies, provide scaffold support, and offer specific feedback for improvement [24]. Professor M began to establish a mentor-teacher role by first making individual contact with all students enrolled in the OLPETE methods course. The instructor described her efforts to build rapport with students during the first week of class. Professor M stated, "[I] make sure that I've heard their voice, [and] know what they want out of this class." Getting to know her audience and understanding their communication preferences was an initial priority. She noted, "I also text. I ask every single student if they mind if I text, and then I send texts to remind them of assignments."

A similar student contact method was noted by Mosier [40] in the description of a mandatory FLVS policy wherein instructors make telephone calls to all students within the first week of the course. Consequently, students who completed the OLPE course indicated that telephone was the preferred method of communication with the instructor. The personal contact with each student appeared to facilitate strong professional connections and influenced student comfort levels within the course. Connor described the benefit of having Professor $M$ establish contact during the first week of the course; he shared, "You get a little nervous going 'Oh man, I do not want to fail this class', but when you talk to the instructor, she would say 'You're doing a good job. Relax. Have some fun. Don't stress out." To the same affect, Ellen was initially "anxious" at the beginning of the course but stated that, "Thankfully [Professor M] is readily available morning, noon and night, on the weekend, at all times. And so she was able to help me; anytime I needed help, she was readily available." Professor $\mathrm{M}$ explained that instructor-tostudent interactions throughout the course were "model[ed] more than talk[ed] about." She established expectations about interactions with students through a course assignment where students construct their own personal introduction videos. Ransdell et al. [16] postulated that concerns about minimal social interaction occurring between peers and teachers within OLPE could be mitigated with the use of video clips and interactive lessons that require communication. Connor described how Professor $M$ modeled the approach and the insight he gained from completing the introduction assignment:

One of the very first things that we did was a Welcome Video. Because, when you are doing an online course, you cannot just put words on a page and expect that students are going to relate to the instructor. They have to have a sense that there is actually a person behind the screen that they can talk to... To make them comfortable and know that 'Wow, this isn't just a teacher, but a person too' and I think learning that kind of stuff you can broaden yourself and really make this course personal to you, because you're the one teaching it.

Connor's description of his initial feelings of the course and subsequent interactions with the instructor exemplify a level of comfort brought to the course by Professor M's proactive communication strategies.

While student-to-instructor interaction was addressed and modeled in the course, communication between students was perceived to be an obstacle. In adult research, services that promote a sense of community through the design of the learning environment have been found to positively influence student success [3]. Interaction among peers has also been shown to increase the likelihood that online students will persist through a course [3]. When asked how she addressed the social and interactive component of OLPE, Professor M stated "...student-to-student is missing in an LMS for many reasons. I mean, the discussion board is really not interactive-it's 'I say something then you say something.' That really doesn't have that dynamic interaction." She elaborated on the potential barriers to meaningful studentto-student dialog when relying on discussion boards:

It is a drain to read [discussion board posts]. In a classroom when there are five or six people talking, it occurs in probably two minutes. Now in a discussion board, somebody has typed a paragraph and a half and you go, 'Do I really want to read the rest of these?'

Similar findings from Kim et al. [41] suggest that facilitating social interaction with the use of discussion boards is not perceived by students to be effective in their online courses. However, within OLPE, discussion forums have been reported as the most widely used method to facilitate social interactions [40]. Thus, rather than using discussion boards to foster interaction among students, Professor $M$ used peer evaluation and mentoring tactics. Students peer-evaluated one another's OLPE units at the midpoint of the course. Connor described the process as:

...Very useful, because somebody else is creating a course just like you, and you want to hear that feedback. 'Hey, I think I like this', 'I never even 
thought of that idea for my own course.' You gain a lot from other people. Other than just a grade.

Similar to the sentiments that underpin the authentic assessments, communication and interaction between students in the OLPETE course were intentional and were facilitated through assignments that required students to interact with the content, peers, and instructor.

\subsection{Transitioning Pedagogical and Content Knowledge Online.} Professor $M$ reflected on her experiences delivering the OLPETE methods course in relation to students' readiness and propensity to deliver content online. This category was the only one that predominately reflected the instructor experience and perspective of the OLPETE methods course. She described students having difficulty transitioning pedagogical and content knowledge to an online environment. In previous research findings, PETE faculty have expressed similar observations in that preservice OLPE instructors will need to differentiate instruction, have an awareness of different learning styles, and become knowledgeable about delivery methods of content and assessment in order to adapt to an online environment [36]. Professor M perceived that online delivery requires teachers be well equipped with content-specific and pedagogical knowledge. She describes the following:

They have to have a pretty good background in their content. You know, the unfortunate thing within online physical education ... is you know immediately if they know their content. ...if they do not ... they cannot teach an online course. That's just the fact of the matter.

For students who did not possess a strong foundation in content or pedagogy prior to entering the OLPETE course, Professor M perceived their transition to online teaching to be more difficult. The notion that teachers who lack professional knowledge, regardless of online or face-to-face settings, are likely to be less effective was reiterated by Professor M: "If they don't have a good background on progression and skill development, and fitness parameters. . .you're going to be a marginal teacher no matter what." Concerns about limited content knowledge were further substantiated by Professor M's perception of student's reliance on external sources, such as textbooks in online PE. She indicated that a contingency of her OLPETE students seemed to perceive online instruction to follow a pattern of traditional behavioral prompts, such as "read chapter...read chapter one through three...take this quiz...module complete." Provided physical education content is unique and movement-oriented, it would be quite difficult to manifest motor skills solely through consumption of written text, thus suggesting a need for creative instruction and pedagogical strategies that will engage online learners with the content. Professor M explained that her students in the past have had difficulty conceptualizing how to teach motor skills online. She stated, "They really don't think that there's a way. A lot of [my students] come in to an online course and think it's just going be 'read this, take this test; read this, instead of trying to get learners to move efficiently and effectively." However, just as preservice physical educators develop pedagogical knowledge across formal learning experiences, it may provide an opportunity for PETE faculty to begin integrating the differences and potential transferability of effective teaching practices from face-to-face to online course design and delivery [36].

Professor M described encounters with OLPETE students whose initial attempts in transitioning discipline-specific content knowledge and pedagogical strategies online have been lackluster. Instead of progressive, interactive skill and knowledge development activities, Professor M suggests that submitted OLPE units often provide learners with informational segments about the history and scoring components of the sport and then send students out to participate in fullsided, unmodified game play. Her feedback, she describes, has had to focus on content development and appropriate progressions of skill more so than the delivery of information in a virtual environment. "They get angry at me," she states, "that I'm using content. I'm talking to them about content because they [say] 'It's just an online class...all you need to tell them is to go out and play." This example reflects challenges in designing and delivering OLPE that may stem from limited pedagogical and content knowledge but may also be a function of students' lack of former experiences with OLPE. With limited exposure to OLPE, students enrolled in the OLPETE course struggled to see how movement-oriented content could translate online without self-direction and full autonomy on part of the learner.

Similar to traditional methods courses, Professor M was confronted with her students' professional dispositions/warrant towards the roles, routines, and norms of the physical education classroom. The students she was working with had a wide range of teaching experience, some with more than 20 years in the school setting, thus having firmly established dispositions towards teaching. In this instance, students' perceptions of OLPE were analogous to the "rollthe-ball-out" physical education teacher who provides limited instruction and promotes high activity, full-sided game play. Preservice teachers typically base their desire to teach on their own past learning experiences. Many have not been exposed to online learning, so they are not always ready to accept the online environment as a viable teaching and learning option [20]. Recognizing this, Professor M elected to approach the course in a manner that refocused her students on the discipline-specific content and learner outcomes. She stated the following:

The most important is their construction of outcomes. And so if one of their outcome is skill, then I know when I look through their unit there [should be] a distinct thread running. If I look and see there's a fitness component moreso [sic] than a skill, then I see another thread that I need to look for.

Her emphasis on content and content development appeared to facilitate changes in student dispositions towards OLPE. Connor described having to "get over" the idea that content is advanced and movement-based and focus on how 
the information can be broken into pieces to help learners interact with it online. He stated the following:

I [was] stressed in thinking that I'd take an advanced idea, such as fitness, and not put enough thought in the beginning. At certain points, I'd go 'Oh wow! How am I going to add this into an online class? Will this work?' I think after you get over that part and know that pretty much anything could be put online, it's just all in presentation. You work hard to figure it out.

From the perspective of the OLPETE students, they were challenged to stretch beyond their comfort zones and develop plans to transition their pedagogy teaching practices online. Connor explained how instructor feedback facilitated his understanding of online content presentation. He stated the following:

[Professor M] would even do split-screen, where she would pull up my video or my work on her screen, as she was talking. She could take her cursor and point and change stuff in my work to show me what I did wrong or what I needed to correct. Basically, [she showed me] how to set up my course.

In Hart's [39] study, students who were interviewed indicated that the quality of feedback from instructors was a factor in their persistence through online course work and had negative perceptions of courses when quality feedback was not provided. The hands-on modeling and specific feedback was also highlighted by Ellen who described herself as a "sponge that was taking it all in." She further explained the following:

Taking that class, I wasn't the expert. I really had no idea what was going on or how it was going to turn out when I took the class. It wasn't until I started teaching the online classes that I started developing my own thoughts about how I could make these better. I had a blast, and it was probably one of the hardest classes that I took, but the most rewarding, as it changed my career... And so I'm thankful that I endured through it, and I got through it, and I succeeded with it, but, man, it was overwhelming at first.

Pedagogical and content knowledge served as the bedrock for students to build upon while actively constructing their own OLPE units. This category was reflected in both students and the instructor perceptions of their experiences across the OLPETE course.

3.4. Navigating Instructional Tools and Technology. The OLPETE methods course was delivered fully online. Professor $\mathrm{M}$ utilized various technologies and tools to deliver content, reinforce concepts, interact with learners, and assess student learning. Regardless, Professor $M$ was adamant, "There's nothing different from an online to a face-to-face [class], except for the tools that you're using." Similar to the ideology expressed by Professor M, Blomeyer suggests "Online learning or e-learning isn't about digital technologies any more than classroom teaching is about blackboards. Elearning should be about creating and deploying technology systems that enable constructive human interaction and support the improvement of all teaching and learning" [42, p. 19]. When asked about her comfort level using technology within the OLPETE course, Ellen responded, "Knowing that she [Professor M] was going to implement a lot of technology into the course, brought me a lot of anxiety because as a non-traditional learner, I had not been using much technology prior to taking the class." Similar sentiments have been expressed by PETE instructors in regard to their students, who they perceive as having a limited functional skillset and generally a superficial understanding of technology's role in teaching [36]. Professor M described, "Everybody is good at selfies and taking videos, but [video] editing, putting in text to enhance the video...they just don't do that very well." She elaborated on her technology integration philosophy: "Tools are only good when they are used appropriately. So, a hammer is good, but it's not so good for doing fine work. So whatever the tool is, it needs to be used appropriately." Previous research has cited that training for online learning should avoid placing an emphasis only on technology, rather than focusing on the pedagogy on online learning [24]. In light of this, Professor $\mathrm{M}$ presented students with a resource she called a "technology toolbox" that showcased a variety of technologies that could align with discipline-specific content, outcomes, and objectives.

In conjunction with the "technology toolbox," Professor $M$ designed an assignment that tasked students with selecting a technology that would enhance the presentation of the $\mathrm{PE}$ content, facilitate learner interaction with the content, and/or contribute to attainment of learning outcomes. After the students had designed and built their OLPE unit, they had to use problem-based learning to select a technology and plan for its use within their unit. Professor M postulated that students would need to problem-solve and determine what tool(s) would be relevant to enhance course content and outcomes.

In accordance with the 2007 NASPE initial guidelines for OLPE, both participants indicated that they selected video-related technologies within their OLPE units and emphasized the importance of video. Ellen indicated that she used Microsoft PowerPoint with embedded voice-overs, YouTube video clips, and mobile devices. She described that the purpose of using these tools was to present content and provide student feedback. During the interview, Ellen shared how she uses video in her own OLPE unit:

I had a student who used a rowing machine. His technique was terrible. Now, I'm a dance teacher; I don't know anything about rowing, but all I had to do was Google some YouTube videos from the National Rowing Association to see what the proper technique was, and I was able to give him feedback. 
Connor also remarked on his use of video within OLPE:

One of the things that I learned ... from this course, [is] this thing called 'Coach's Eye' where you can video tape whatever you're doing and you can actually send it to whoever you want. So, for example, if I have an athlete that's videotaping themselves shooting a basketball, they could actually send it to me through the Coach's Eye [app]... and I could evaluate what they're doing in slow motion and give them instant feedback. And actually, I could voice record in it and give them feedback to help them correct [their performance] without me being there. So yeah, I have used that at my school.

While these student examples describe the process of overcoming the transactional distance between themselves and students with the use of video technology, critics suggest that video feedback in OLPE cannot fully replace the feedback given in a traditional physical education setting. Ransdell et al. [16] contend that OLPE instructors have the ability to analyze a student performing skill remotely; however, providing immediate, skill-related feedback becomes more difficult to do within an online setting. In response to this contextual challenge, Ellen described the effects that her use of video had on her learners, "I say to them, I need you to videotape yourself doing ten minutes of aerobics, they're like, 'Oh, okay, she means business,' [because] I'm definitely going to see what they're doing." However, she did indicate that the use of video in OLPE has been perceived by students as intimidating:

I'll be real honest with you, most of the time that online PE course draws the people that don't want to exercise in front of anyone. They have this misconception that, 'Oh, it's an online course, they're never going to see me do anything. I'm passive - I'm anonymous to them because I'm five hundred miles away.' I tell them on week number one of the semester, "This is what's expected of you. If this is not what you were expecting out of the class, you can drop it. But I'm telling you right from the get-go, this is what you're going to have to do. So you know up front what I expect out of you." And I do have some people drop.

In addition to using video to verify physical activity participation, Ellen indicated that video allowed her to connect to her students, "It helped me get to know my students better. Because I was watching them on a weekly basis, I was getting to know them, I saw the struggle that some of my couch potatoes were having." Connor echoed these sentiments relative to video-based technologies stating, "I don't think you can have a very good online program if you do not use video...I think that that's very important. I don't think that an online course is just reading."

From the students' perspective, the technology toolbox provided by Professor M spurred them onto their own ideas for technology use in their OLPE units. By the end of the course, the instructor stated that students "should have a toolbox of technologies that they are comfortable with." However, she was adamant that "it's not the technology that makes the teacher, it's the knowledge of the content and being able to appropriately present it, [no matter] the venue you're using."

When asked if any piece of technology was crucial for OLPETE, Professor M stated, "A good LMS will make or break [it], that's for sure." Considering this, it is interesting to note that most of the technology-related anxiety expressed by the students was in relation to learning how to use the LMS. Similarly, students enrolled in OLPE within the Goc Karp and Woods [43] study expressed difficulties in learning to use the LMS. Consequently, the LMS has been a tool identified as crucial for teacher education programs to expose their preservice teachers to before teaching online [44]. The LMS is at the heart of an online course since it is where students access course content (instructional materials, audio/video, presentations, digital text books, etc.), discussion boards, and quizzes and submit assignments and it allows teachers to manage the class, upload assignments, develop projects, create discussion forums, and score/grade. Professor M elaborated, "Some students were uncomfortable merely setting up an online class, which really-you can't hurt it. I mean it's pretty much 'stick things here, move things here and it's a shell,' use it or don't use it." Ellen explained her initial apprehensions using an LMS, "When I signed up to take online classes, I didn't even know what Blackboard was, and so for me to jump into the class was like putting the cart before the horse." Similarly, when asked about his first impressions of the LMS, Connor responded, "Well, it's the only one I know, so I don't really have anything to compare it to other than kind taking courses on Blackboard, but not teaching through it..." To address this, Professor M focused heavily on modeling and explaining instructional practices and decisions while creating opportunities for learners to assume the role of instructor within the course.

\section{Limitations}

It is important to acknowledge limitations to the current study. According to Ornek [45], the validity of phenomenographic research is contingent upon three factors: (1) logic of categories, (2) correspondence of results to previous research, and (3) probability of categories to be considered. First, the sample came from a single, midlevel midwestern university with a small-to-moderate student population (approx. 5,800). While the study may provide some initial insights into the conceptions of teaching and learning within an OLPETE methods course, it is important to recognize that categories emerged from one-time 60-90-minute interviews from each of the three participants.

Second, it is important to note that limitations exist in regard to correspondence between the results and what is currently known in OLPE due to it being an underresearched area within the field of physical education [9]. To support the categories discussed in the results, research from the field of distance education was utilized to supplement discussion 
where OLPE literature was lacking. However, LindblomYlänne et al. [46] have suggested that approaches to teaching are affected by both context and subject discipline. Therefore, the ways of conceiving an OLPETE methods course described by the interviewees do not reflect an exhaustive range of possible online teacher education instructional methods. While the results are not claimed to be generalizable due to the above state factors, they do represent the first efforts in describing the perceptions and experiences of preservice teachers preparing to be online physical educators.

\section{Conclusions}

These initial findings reveal several ideas for PETE faculty to be aware of and consider when planning to integrate online teaching methods courses. Although there are mixed reviews about the efficacy of instructing physical education online, these suggestions could benefit those training online physical educators in the future as more school districts adopt online instruction [7, 47]. First, students enrolled in the OLPETE methods course faced initial apprehension to the idea of transferring physical education online. Students likely felt this way due to having no previous experience with OLPE or even how an online course is taught from the instructor's perspective. Similarly, Williams [19] found that practicing OLPE instructors were initially hesitant and skeptical about instructing physical education online when they started. The OLPE instructors' apprehension was attributed to a lack of online training in their undergraduate preparation and professional development early in their careers [19]. Despite being a graduate-level class, the OLPETE methods instructor used a "model the master" approach to ease concerns and demonstrate effective online instructional practices. In support of this "model the master" practice employed by Professor M, Bork and Rucks-Ahidiana [48] found that online instructors lacked opportunities and venues to observe the instructional practices of their colleagues within an online teaching setting. The online instructional practices demonstrated were then later emulated in student's major course projects. Professor M's instructional method is in line with Bork and Rucks-Ahidiana's [48] suggestion that novice online instructors first work with "master" online teachers during initial course development and refinement. As a function of observing the instructor's behaviors and being tasked to create their own OLPE units, students became more comfortable applying discipline-specific, movementbased content into the unique online setting, which facilitated a greater level of ownership of their own learning.

Second, throughout the course, the interactions between the instructor and students appeared to be crucial. These interactions fostered a cognitive apprenticeship that began with the initial contact made by the instructor and then intentionally integrated throughout the course experience. Personalized communication has been cited in the literature as a factor contributing to online student persistence through course work [11, 17, 19, 40, 48, 49]. Bork and Rucks-Ahidiana [48] noted that students felt like they were "talking to a wall" if the online instructor was nonresponsive and did not interact with them through discussion boards or email.
Conversely, Hew [50] found that students reported a greater feeling of connectedness and commitment to online courses when the instructors held "webcast" office hours. Office hours consisted of a one-hour live interactive discussion among the professor and students that could be accessed by telephone, discussion forums, Twitter, Facebook, and YouTube [50]. Specific to OLPE, Mosier [40] suggested that creative medians of student-to-student interactions can be facilitated by collaboration on projects or peer tutoring. The benefits of doing so were evident in Professor M's facilitating student collaboration as a part of the major course project by having students peer-evaluate one another's OLPE units. Future OLPETE methods instructors should consider using similar personalized communication methods to foster interactivity and demonstrate effective teaching practices that can build a sense of community and alleviate student apprehension.

Third, investigation of the OLPETE methods course revealed that student's readiness to deliver OLPE was greatly affected by their depth of content and pedagogical knowledge. Students who lacked the proper physical education content and pedagogical knowledge prior to entering the course appeared to struggle in transitioning physical education units online. This finding concurs with Williams's [19] recommendation that, in the same rationale as in a traditional public school setting, online instructors should be certified in the discipline-specific areas they are teaching. Also affecting students' comfort level with the transition were professional dispositions and subjective warrants towards their roles as physical education instructors. In Bork and Rucks-Ahidiana's [48] concluding remarks regarding instructors' perception of online presence and pedagogy, the authors stated that, "Given the diversity of philosophies, preparation, and personalities of instructors, these differing views are not surprising or distinct to the online space, but they are exacerbated in distance learning courses" [p. 23]. Future OLPETE methods instructors may find success with students who possess custodial warrants towards physical education and online programming, by placing an emphasis on physical education content, online content development, student reflection, hands-on modeling, and individual specific feedback. PETE programs may also want to consider OLPETE methods as a higher level teaching practice and develop the course either as an undergraduate field-based experience or as a graduatelevel experience.

Fourth and finally, student's technology readiness should be considered when developing or instructing an OLPETE methods course. The benefits of technological innovation have the potential to quell concerns in the practice of OLPE. However, simple adoption of technology does not ensure the quality and effective OLPE delivery. It should not be assumed that students already possess the knowledge to effectively utilize technology in an online course setting. Studies have suggested that the assumption of generational familiarity with computers and mobile technology possessed by digital natives does not necessarily translate to online education $[1,10,15,19,43,48,49]$. Technology in the OLPETE methods course should be connected with content in a meaningful way to meet objectives, assess and deliver content more efficiently, or solve an instructional problem. Hew [50] 
identified problem centric learning as a factor influencing students' online course satisfaction and engagement. With simple-to-understand expositions, problem centric learning provided students with an active and engaging experience that enabled them to individually construct personal meaning from the courses content [50]. Problem-based learning strategies should be considered in order to demonstrate the use and effectiveness of properly integrated technology in an OLPETE course.

Wyant et al. [51] expressed that a more holistic technology integration approach is needed in PETE. Instead of technology being only discussed in generalized terms or one specific course in a program, a holistic approach would purposely infuse technology throughout a PETE curriculum [51]. Williams [19] suggested that preparing preservice physical educators for online teaching would provide them with a well-rounded experience and knowledge base. With the emergence of OLPE, a holistic approach would need to intentionally expose preservice teachers to technology that has practical applications that enhance teaching and learning in both the gymnasium and online domain.

\section{Conflicts of Interest}

The authors declare that they have no conflicts of interest.

\section{References}

[1] S. Bennett, K. Maton, and L. Kervin, “The'digital natives' debate: a critical review of the evidence," British Journal of Educational Technology, vol. 39, no. 5, pp. 775-786, 2008.

[2] D. Oblinger and J. Oblinger, "Is it age or IT: first steps towards understanding the net generation," in Educating the Net Generation, D. Oblinger and J. Oblinger, Eds., pp. 2.1-2.20, EDUCAUSE, Boulder, Colo, USA, 2005, Retrieved January 31, 2017, from http://net.educause.edu/ir/library/pdf/pub7101.pdf.

[3] K. L. Rice, "A comprehensive look at distance education in the K-12 context," Journal of Research on Technology in Education, vol. 38, no. 4, pp. 425-448, 2006.

[4] E. Allen and J. Seaman, Changing Course Ten Years of Tracking Online Education in The United States, Sloan Center for Online Education, 2012.

[5] M. Barbour, "Researching K-12 online learning: what do we know and what should we examine?" Distance Learning, vol. 7, no. 2, pp. 7-12, 2010.

[6] Y. Beldarrain, Engaging the 21st century learner: an exploratory study of the relationship between interaction and achievement in the virtual high school [Ph.D. thesis], Capella University, Minneapolis, Minn, USA, 2008.

[7] B. Mohnsen, "Implementing online physical education," Journal of Physical Education, Recreation \& Dance, vol. 83, no. 2, pp. 4247, 2012.

[8] SHAPE America, Shape of The Nation: Status of Physical Education in The USA, SHAPE America, Reston, Va, USA, 2016.

[9] D. N. Daum and C. Buschner, "Research on teaching blended and online physical education," in Handbook of Research on $\mathrm{K}$ 12 Online and Blended Learning, R. Ferdig and K. Kennedy, Eds., pp. 201-221, ETC Press, Pittsburgh, Pa, USA, 2014.

[10] J. D. Brewer, The impact of a web-based versus face-to-face instructional format of a lifetime fitness course on students' wellness knowledge, attitudes and behaviors and levels of healthrelated physical fitness [Ph.D. thesis], Kansas State University, Manhattan, Kan, USA, 2001.

[11] B. Mosier and S. Lynn, "An initial exploration of a virtual personal fitness course," Online Journal of Distance Learning Administration, vol. 15, no. 3, 2012.

[12] NASPE, "Initial guidelines for online physical education," 2007.

[13] E. Allen, J. Seaman, and R. Garrett, Blending in The Extent and Promise of Blended Education in The United States, Sloan Consortium, Needham, Mass, USA, 2007.

[14] B. J. Cardinal, "How can we help college and university students stay active and healthy for life?" The Journal of Physical Education, Recreation \& Dance, vol. 83, no. 8, p. 53, 2012.

[15] D. N. Daum and C. Buschner, "The status of high school online physical education in the United States," Journal of Teaching in Physical Education, vol. 31, no. 1, pp. 86-100, 2012.

[16] L. B. Ransdell, K. Rice, C. Snelson, and J. Decola, "Online health-related fitness courses," The Journal of Physical Education, Recreation \& Dance, vol. 79, no. 1, pp. 45-52, 2008.

[17] M. Trent, Investigating virtual personal fitness course alignment with the national guideline for online physical education (Doctor of Philosophy Dissertation) [Ph.D. thesis], Georgia State University, Atlanta, Ga, USA, 2016.

[18] B. Mosier, "Meeting PETE students in their world: tracking physical activity through technology," The Journal of Physical Education, Recreation \& Dance, vol. 85, no. 3, pp. 46-49, 2014.

[19] L. Williams, A case study of virtual physical education teachers' experiences in and perspectives of online teaching, University of South Florida, Tampa, Fla, USA, 2014.

[20] I. Quillen, "E-learning delivery debated," Education Week, vol. 29, no. 30, 2010.

[21] J. Rink, Teaching Physical Education for Learning, McGraw-Hill, Boston, Mass, USA, 2013.

[22] A. Gibbone and K. Mercier, "Accomplishing PETE learning standards and program accreditation through teacher candidates' technology-based service learning projects," The Journal of Physical Education, Recreation \& Dance, vol. 85, no. 5, pp. 1822, 2014.

[23] S. Juniu, "Pedagogical uses of technology in physical education," The Journal of Physical Education, Recreation \& Dance, vol. 82, no. 9, pp. 41-49, 2011.

[24] K. Kennedy and L. Archambault, "Offering preservice teachers field experiences in K-12 online learning: a national survey of teacher education programs," Journal of Teacher Education, vol. 63, no. 3, pp. 185-200, 2012.

[25] F. Marton, "Phenomenography: a research approach to investigating different understandings of reality," Journal of Thought, vol. 21, no. 3, pp. 28-49, 1986.

[26] S. Merriam, Qualitative Research in Practice. Examples for Discussion and Analysis, Jossey-Bass, San Francisco, Calif, USA, 1st edition, 2002.

[27] M. Q. Patton, Qualitative Research and Evaluation Methods, Sage, Thousand Oaks, Calif, USA, 3rd edition, 2002.

[28] G. S. Åkerlind, "A phenomenographic approach to developing academics' understanding of the nature of teaching and learning," Teaching in Higher Education, vol. 13, no. 6, pp. 633-644, 2008.

[29] J. W. Creswell, Qualitative Inquiry and Research Design: Choosing among Five Approaches, Sage Publications, Los Angeles, Calif, USA. 
[30] B. Glaser and A. Strauss, The Discovery of Grounded Theory, Weidenfeld and Nicholson, London, UK, 1967.

[31] A. Strauss and J. Corbin, Basics of Qualitative Research Techniques and Procedures for Developing Grounded Theory, Sage Publications, London, UK, 2nd edition, 1998.

[32] N. K. Denzin and Y. S. Lincoln, The SAGE Handbook of Qualitative Research, Sage Publications, London, UK, 4th edition, 2011.

[33] F. Marton and S. Booth, Learning And Awareness, Lawrence Erlbaum Associates, Mahwah, NJ, USA, 1997.

[34] G. S and G. S. Åkerlind, "Variation and commonality in phenomenographic research methods," Higher Education Research Development, vol. 24, no. 4, pp. 321-334, 2005.

[35] YS. Lincoln and E. G. Guba, Naturalistic Inquiry, Sage Publications, Newbury Park, Calif, USA, 1985.

[36] D. N. Daum, Physical education teacher educator's attitudes toward and understanding of online physical education [Ph.D. thesis], University of Illinois, Urbana-Champaign, Ill, USA, 2012.

[37] B. J. Kooiman, D. P. Sheehan, M. Wesolek, and E. Retegui, "Moving online physical education from oxymoron to efficacy," Sport, Education and Society, vol. 22, no. 2, pp. 1-17, 2015.

[38] M. Wicks, A National Primer on K-12 Online Learning Version 2, International Association for K-12 Learning, Vienna, Va, USA.

[39] C. Hart, "Factors associated with student persistence in an online program of study: a review of the literature," Journal of Interactive Online Learning, vol. 11, no. 1, pp. 19-42, 2012.

[40] B. Mosier, A descriptive study of Florida virtual school's physical education students: An initial exploration [Ph.D. thesis], The Florida State University, Tallahassee, Fla, USA, 2010.

[41] P. Kim, F. H. Kim, and A. Karimi, "Public online charter school students: choices, perceptions, and traits," American Educational Research Journal, vol. 49, no. 3, pp. 521-545, 2012.

[42] R. Blomeyer, Online Learning for K12 Students: What Do We Know Now? North Central Regional Educational Laboratory, Naperville, Ill, USA, 2002.

[43] G. G. Karp and M. L. Woods, "Wellness NutriFit online learning in physical education for high school students," Journal of Interactive Online Learning, vol. 2, no. 2, 2003.

[44] N. E. Davis and M. D. Roblyer, "Preparing teachers for the 'schools that technology built"' Journal of Research on Technology in Education, vol. 37, no. 4, pp. 399-409, 2005.

[45] F. Ornek, "An overview of a theoretical framework of phenomenography in qualitative education research: An example from physics education research," Asia-Pacific Forum on Science Learning Teaching, vol. 9, no. 2, pp. 1-14, 2008.

[46] S. Lindblom-Ylänne, K. Trigwell, A. Nevgi, and P. Ashwin, "How approaches to teaching are affected by discipline and teaching context," Studies in Higher Education, vol. 31, no. 3, pp. 285-298, 2006.

[47] S. L. Price, "Hiring considerations and training in physical education pedagogy: current trends in physical activity grades K-12," Journal of Physical Education, Recreation \& Dance, vol. 86, no. 3, pp. 5-6, 2015.

[48] R. Bork and Z. Rucks-Ahidiana, Role Ambiguity in Online Courses: An Analysis of Student and Instructor Expectations, Community College Research Center Teachers College. Columbia University, New York City, NY, USA, 2013.

[49] Kane, "The dog ate my disk: teacher and student perspective of an online personal fitness course," Flordia Alliance of Health Physical Education Recreation and Dance, vol. 42, no. 2, pp. 8-12, 2004.
[50] K. F. Hew, "Promoting engagement in online courses: what strategies can we learn from three highly rated MOOCS," British Journal of Educational Technology, vol. 47, no. 2, pp. 320-341, 2016.

[51] J. D. Wyant, E. M. Jones, and S. M. Bulger, "A mixed methods analysis of a single-course strategy to integrate technology into PETE," Journal of Teaching in Physical Education, vol. 34, no. 1, pp. 131-151, 2015. 


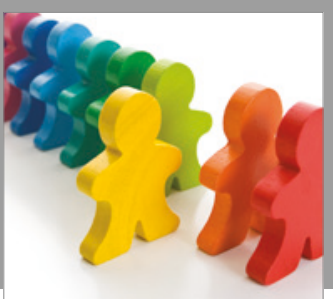

Autism

Research and Treatment
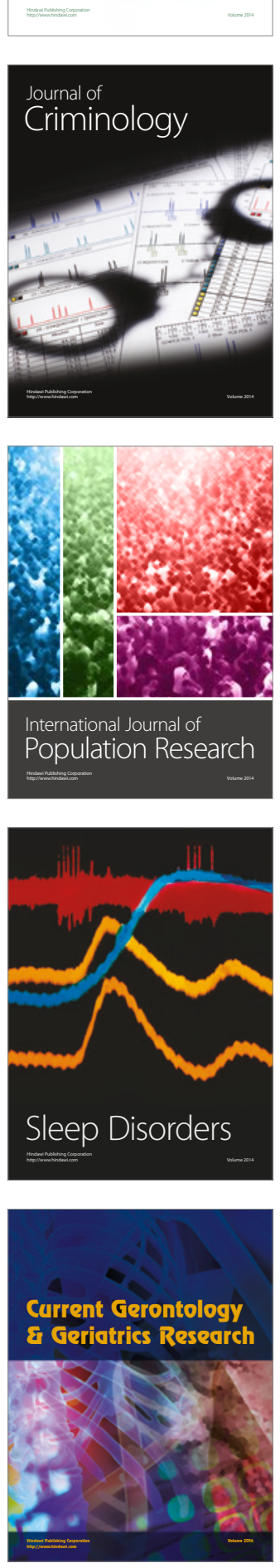

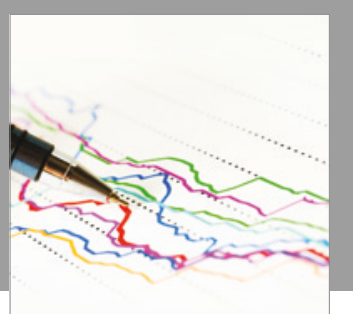

Economics

Research International

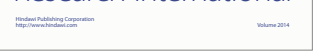

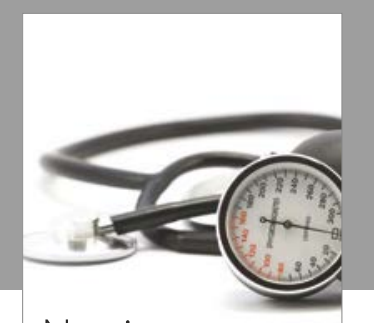

Nursing

Research and Practice

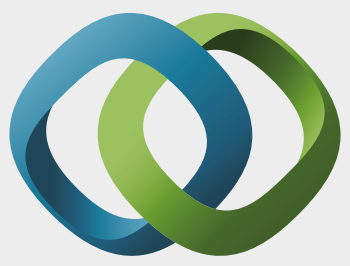

\section{Hindawi}

Submit your manuscripts at

https://www.hindawi.com
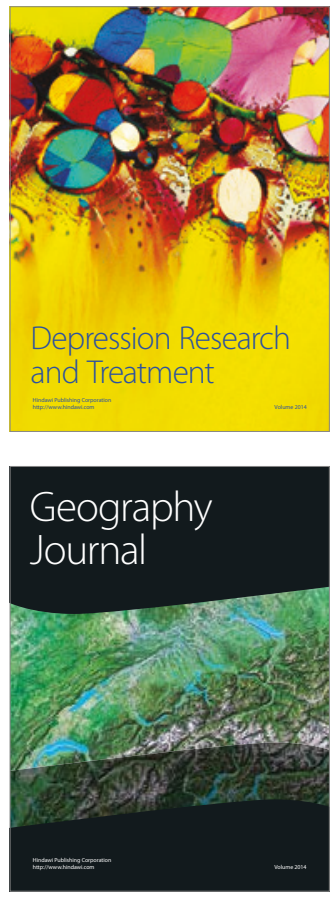
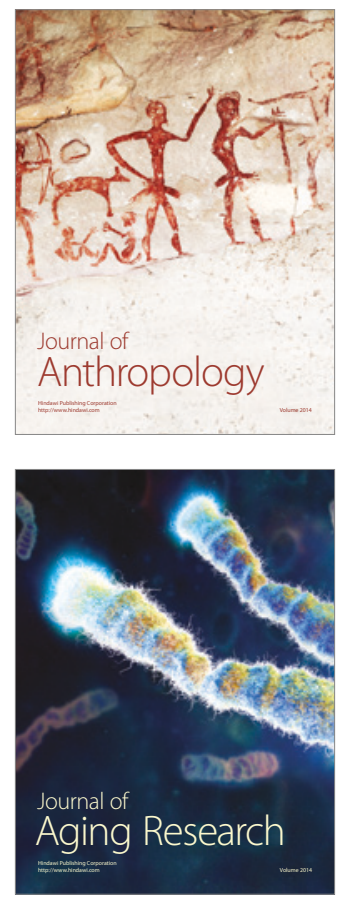
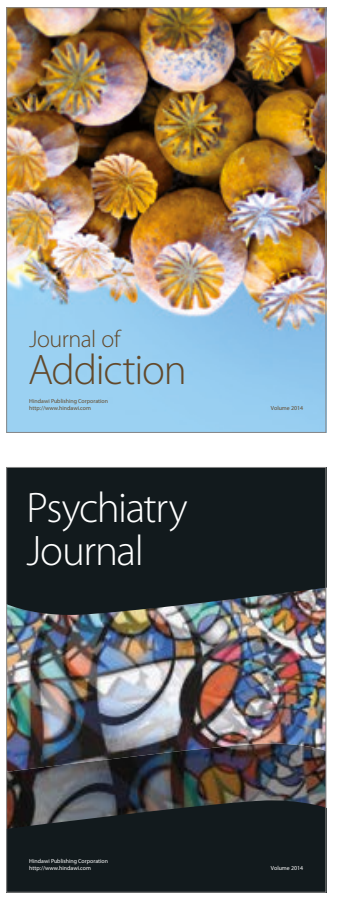

Child Development

Research

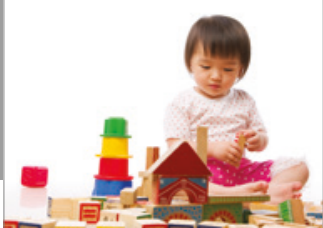

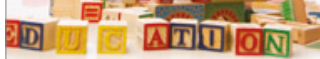
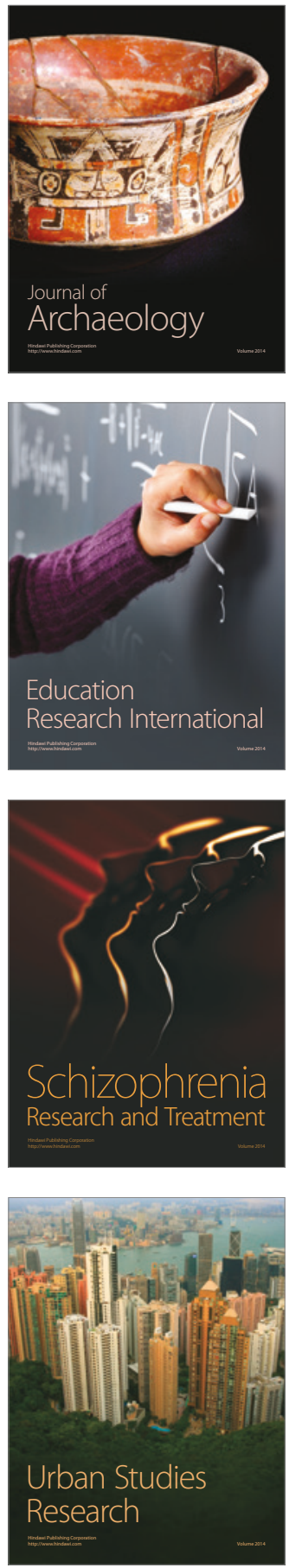